University of South Florida

DIGITAL COMMONS

Digital Commons @ University of

@ UNIVERSITY OF SOUTH FLORIDA

South Florida

Mental Health Law \& Policy Faculty

Publications

Mental Health Law \& Policy

4-1993

\title{
Detection of Deception in Law Enforcement Applicants: A Preliminary Investigation
}

\author{
Randy Borum \\ University of Massachusetts Medical Center, wborum@usf.edu \\ Harley Stock \\ Palm Bay Police Department
}

Follow this and additional works at: https://digitalcommons.usf.edu/mhlp_facpub

Part of the Clinical Psychology Commons, Defense and Security Studies Commons, International Relations Commons, Military and Veterans Studies Commons, and the Peace and Conflict Studies Commons

\section{Scholar Commons Citation}

Borum, Randy and Stock, Harley, "Detection of Deception in Law Enforcement Applicants: A Preliminary Investigation" (1993). Mental Health Law \& Policy Faculty Publications. 547.

https://digitalcommons.usf.edu/mhlp_facpub/547

This Article is brought to you for free and open access by the Mental Health Law \& Policy at Digital Commons @ University of South Florida. It has been accepted for inclusion in Mental Health Law \& Policy Faculty Publications by an authorized administrator of Digital Commons @ University of South Florida. For more information, please contact digitalcommons@usf.edu. 


\section{Springer}

Detection of Deception in Law Enforcement Applicants: A Preliminary Investigation Author(s): Randy Borum and Harley V. Stock

Reviewed work(s):

Source: Law and Human Behavior, Vol. 17, No. 2 (Apr., 1993), pp. 157-166

Published by: Springer

Stable URL: http://www.jstor.org/stable/1394021

Accessed: 05/12/2011 15:30

Your use of the JSTOR archive indicates your acceptance of the Terms \& Conditions of Use, available at http://www.jstor.org/page/info/about/policies/terms.jsp

JSTOR is a not-for-profit service that helps scholars, researchers, and students discover, use, and build upon a wide range of content in a trusted digital archive. We use information technology and tools to increase productivity and facilitate new forms of scholarship. For more information about JSTOR, please contact support@jstor.org. 


\title{
Detection of Deception in Law Enforcement Applicants
}

\author{
A Preliminary Investigation*
}

\author{
Randy Borum $\dagger$ and Harley V. Stock $\ddagger$
}

Using the MMPI and the IPI, the present study examined the differences in psychometric defensiveness between two groups of law enforcement applicants: applicants identified as being deceptive and a comparison group of candidates for whom no deception was indicated. Significant differences were found on the traditional validity (minimization) scales for both instruments as well as several supplemental scales and indexes from the MMPI. A new index (Es-K) from the MMPI showed a highly significant difference between groups and good classification accuracy. The results suggest that deceptive applicants show more defensiveness on psychometric testing and that test results may assist in raising the index of suspicion for detecting deception in law enforcement applicants.

It is generally agreed that honesty and integrity are at the cornerstones of being a police officer (Pendergrass, 1987). In order to identify the best applicant, it has been recommended by national advisory panels that police officers be psychologically screened to assure that only the most suitable are chosen "to serve and to protect" (National Advisory Commission on Criminal Justice Standards and Goals: Police, 1967). The courts have determined that police agencies have a right to conduct psychological evaluations (McCabe v. Hoberman, 1969; Conte v. Horcher, 1977) and may be held liable for employees who were not properly evaluated (Bonsignore v. City of New York, 1981).

\footnotetext{
* The authors wish to thank Michael Nietzel and two anonymous reviewers for their helpful comments on an earlier draft of this manuscript, and Ronald Roesch for his editorial assistance. Requests for reprints should be sent to Randy Borum, Forensic Training and Research Center, University of Massachusetts Medical Center, Department of Psychiatry, 55 Lake Avenue, North, Worcester, MA 01655.

$\dagger$ Palm Bay Police Department.

$\ddagger$ Seafield 911 .
} 
Typically, psychologists are asked to screen out preemployment candidates who are at high risk for job-related problems or who could pose a threat to public safety. These evaluations typically involve a clinical interview and at least two objective tests such as the Minnesota Multiphasic Personality Inventory (MMPI) and the Inwald Personality Inventory (IPI); (Inwald, 1985). However, the psychological evaluation is only one component of a larger police selection process. Because of the inherent cost factor, psychological screening is often the last step in a procedure that includes an extensive application form, background investigation, oral board interview, and sometimes a drug screen and polygraph testing. One implied purpose of this rigorous process is to identify individuals who may be dishonest and deceptive. Specifically, assessing the veracity of an applicant's self-report is also an important aspect of the psychological evaluation (Heilbrun, 1992).

Though most psychometric instruments like the MMPI and the IPI have validity scales constructed to detect defensiveness, these measures are not "lie detectors." They do, however, provide information about the way in which the respondent is trying to present him or herself. For example, the Guardedness scale (GD) on the IPI was designed "to identify persons who have minimized shortcomings, denied faults, and answered items in a 'socially desirable' direction" (Inwald, Knatz, \& Husman, 1982, p. 6). On the MMPI, the two most commonly used scales to assess defensiveness are the $\mathrm{L}(\mathrm{Lie})$ scale and the $\mathrm{K}$ (Defensiveness) scale (Meehl \& Hathaway, 1946). The L scale "was designed to detect rather unsophisticated and naive attempts on the part of the individuals to present themselves in an overly favorable light" while "the K scale of the MMPI was designed to identify clinical defensiveness"' (Graham, 1987, p. 6).

Subsequently, several supplemental validity scales and indexes have been developed for the MMPI. One of the earliest efforts focused on comparing endorsement of obvious items (those which are easily identified as relating to psychopathology) to endorsement of subtle items (items whose relationship to psychopathology is not as easy to detect). This resulted in the Wiener-Harmon Obvious and Subtle (O-S) scales for the MMPI (Wiener, 1948). The rationale for this approach was that real patients will endorse both obvious and subtle items/ symptoms of their disorder. However, individuals who are malingering or exaggerating psychopathology would endorse a large number of obvious items, but significantly fewer subtle items. The opposite pattern would be seen in defensive individuals. Since there are separate O-S scales for 5 of the 10 clinical scales, a total score would be derived by subtracting subtle scale $T$ scores from the obvious scale $T$ scores for each scale and adding the sum of the differences. A large negative number would suggest defensiveness whereas a large positive number would suggest exaggeration.

Although the research on the O-S scales for detection of "faking good" has been somewhat limited, and opinions regarding their use have been varied (Weed, Ben-Porath, \& Butcher, 1990), they do appear to have some potential for this purpose (Gendreau, Irvine, \& Knight, 1973; Harvey \& Sipprelle, 1976; Peterson, Clark, \& Bennett, 1989; Wasyliw, Grossman, Haywood, \& Cavanaugh, 1988). In fact, one study by Grossman, Haywood, Ostrov, Wasyliw, and Cavanaugh (1990) 
has shown the Subtle-Obvious scales to be sensitive to motivational sets among police officers referred for fitness-for-duty evaluation.

Another MMPI indicator that has shown some promise for detection of "faking good"' is the Positive Malingering (Mp) scale developed by Cofer, Chance, and Judson (1949). The Mp scale comprises 34 empirically derived items which were susceptible to defensiveness and insensitive to malingering (faking bad). In the original study, Cofer et al. (1949) found that a cutting score of 20 or more correctly classified $96 \%$ of the honest records and $86 \%$ of positively malingered (instructions to make the best possible impression) records. Subsequent research has also found the Mp scale to be effective in identifying "faking good" on the MMPI (Grow, McVaugh, \& Eno, 1980; Kelly \& Greene, 1989; Wales \& Seeman, 1968).

One other validity index from the MMPI which is commonly used is the F-K Index, also called the Gough Dissimulation Index (Gough, 1950). This score is derived by subtracting the raw score of the $\mathrm{K}$ scale from the raw score of the $\mathrm{F}$ scale. Although this index is more often used to detect malingering (faking bad), Gough also hypothesized that any score less than zero would suggest defensiveness or faking good. However, subsequent studies have shown that normal individuals typically achieve a mean score that is closer to - 10 (Colligan, Osborne, Swenson, \& Offord, 1983; Greene, 1986). One problem with this index is that it is difficult to distinguish between well-adjusted individuals who are not experiencing psychological distress and individuals who are being defensive (Greene, 1988). Indeed, it has been difficult to identify cutting scores that distinguish normal from defensive profiles, resulting in somewhat limited effectiveness of the F-K Index for detection of defensiveness (Cofer et al., 1949; Grayson \& Olinger, 1957; Hunt, 1948; Johnson, Klinger, \& Williams, 1977).

Using logic similar to that of Gough in developing the F-K Index, the authors have proposed a new index, which may be more sensitive to defensiveness or "faking good." This index was created by subtracting the $T$ score of the $\mathrm{K}$ scale from the $T$ score of the Ego Strength (Es) scale. The Es scale was originally developed by Barron $(1953,1956)$ to predict responsiveness to psychotherapy and general ability to cope with problems. He believed that it "measured a general factor of capacity for personality integration or ego strength" (Greene, 1980, p. 191). According to Graham (1987), high Es scores are indicative of an individual who is stable, reliable, responsible, and self confident. High $\mathrm{K}$ scores are more indicative of defensiveness in an individual who is trying to give an appearance of adequacy, control, and effectiveness, and who lacks self-insight and selfunderstanding. However, these two scores are considered to be related, and Caldwell (1988) suggests that interpretation of the Es scale is most effective when seen in comparison to the $\mathrm{K}$ scale. The positive characteristics of "personal organization" associated with high Es scores seem to be more prominent when Es is increasingly higher than $\mathrm{K}$. To some extent, both scales measure the effective operation of psychological defenses to bind psychological distress. Consequently, the comparison is made to differentiate the healthy defensiveness from the intentional effort to ignore or minimize difficulties. This is identified as the Es-K Index.

The purpose of the present study was to examine the relationship between psychometric indicators of defensiveness and conscious deception in law enforce- 
ment applicants. Although these scales were not designed to be "lie detectors," they do suggest when individuals are trying to present themselves in an overly favorable manner. The underlying principle is quite similar. The applicant is distorting (withholding or fabricating) self-report information in order to make him or herself appear more favorable as an applicant. Therefore, it was hypothesized that there may be a relationship between these two factors. If this is true, then the validity of these scales is extended, and they could potentially be used to raise the index of suspicion for deception in these preemployment screenings.

In this study we examine a unique population: applicants for law enforcement positions who were found to be deceptive and subsequently admitted during the clinical interview that they had intentionally lied in one or more areas of the application process. We compare them to a group of police applicants in whom there was no admitted deception and none could be detected. We were interested in the following questions:

1. Do these two groups differ on the validity indexes of the MMPI and the IPI?

2. Do any of these scales or indexes discriminate between the groups so that they could be used to identify candidates who need closer scrutiny?

\section{METHOD}

\section{Participants}

Participants were 36 applicants for law enforcement positions of police officer or deputy sheriff. The applicants had applied to law enforcement agencies throughout Michigan, including both large and small departments. Each of them had been referred to a contracted center or practice for psychological evaluation as a component of their screening process. All evaluations used in the study had been conducted over the past 7 years and included an MMPI, an IPI, and a structured clinical interview lasting approximately one hour. The evaluating psychologist had the test results and the completed application form available at the time of the interview.

The criterion for deception was an admission by applicants that they knowingly lied or provided false information in completing the application or background questionnaire in order to appear more favorable or because they thought the information would "look bad." Areas of deception included both minor shortcomings and more significant problems, and were typically related to job history, school history, and drug use. These admissions typically occurred when the applicant was confronted with inconsistencies in collateral information available to the psychologist. In their deception, each of these applicants had falsified sworn and notarized documents. Eighteen applicants who met this criterion were identified, and these subjects comprised the deceptive group. A second group of 18 applicants was drawn randomly from the files. Each of these applicants had denied any deception in completing their application or background questionnaire, and there was no contradictory information discovered from other documents or collateral sources of information to indicate deceptiveness. These subjects comprised the comparison group. 
The authors note that while all of the deceptive individuals in this study admitted to lying at various stages of the application process, it is certainly possible that some applicants in the comparison group also intentionally falsified information but were not detected.

The total sample was $83.3 \%$ male and $16.7 \%$ female. Racial composition was $86.1 \%$ White, $11.1 \%$ Black, and 2.8\% Hispanic. Age ranged from 20 to 35 years with the average age being 25.6. There were no significant differences between the two groups with respect to age, gender, or race.

All applicants had completed a medical examination, an extensive application form, physical agility testing, and oral board interviews prior to their psychological screening. They were also required to meet a minimum educational requirement of a high school diploma or its equivalent.

\section{Instruments}

Psychological testing for each applicant included completion of two psychometric instruments. The MMPI is a 566 item, true-false, paper-and-pencil inventory developed by Hathaway and McKinley (1967) to assess clinical psychopathology. Its primary scales consist of three validity and 10 clinical scales measuring a range of psychopathological symptoms and syndromes. The two validity scales which are related to minimization/defensiveness are the $\mathrm{L}$ scale and the $\mathrm{K}$ scale. In addition, several of the supplemental validity indexes were examined in the present study including (a) the F-K Index (Gough, 1950), (b) the Obviousminus-Subtle (O-S) scales (Wiener, 1948), (c) the Positive Malingering Scale (Mp) (Cofer et al., 1949), and (d) the Es-K Index proposed by the authors.

The IPI is a 310-item, true-false, paper-and-pencil inventory designed to measure dimensions of personality and behavior relevant to law enforcement (Inwald et al., 1982). It comprises 26 scales including one validity scale called the GD (Guardedness) scale.

\section{Procedure}

The method of data acquisition was archival. The deceptive applicants were identified by information in the psychological report which indicated that the individual admitted to being deceptive with regard to his or her application and/or background inquiry. Over 300 files were reviewed from multiple contract centers to identify the 18 deceptive applicants and all necessary test results. The comparison group was drawn at random from a group of applicants whose psychological reports did not indicate an admission of deception. Because of the relatively small number of subjects in the study, the scope of investigation was limited to seven scales including the L, K, Mp, O-S total, F-K Index, and Es-K Index from the MMPI and the GD scale from the IPI.

\section{RESULTS}

A separate analysis of variance was run for each of the seven variables. We hypothesized that the deceptive applicants would have higher scores on $\mathrm{L}, \mathrm{K}$, 
Mp, and GD, but lower scores on O-S total, F-K Index, and Es-K Index. Lower scores on the latter three variables (typically in the negative range) would indicate greater defensiveness.

Results of the ANOVAs revealed significant differences for five of the seven scales and indexes. On the L scale and the K scale, both MMPI validity scales designed to measure minimization, scores were significantly different between the groups, with the deceptive group scoring higher on each. The deceptive group also scored significantly higher on the Positive Malingering $(\mathrm{Mp})$ scale of the MMPI, and on the GD scale, the IPI validity scale that measures guardedness. A highly significant difference was also found for the Es-K index, with the deceptive group scoring significantly lower (in the expected direction). No significant differences were found for either the O-S total score or the F-K index on the MMPI. Means, standard deviations, and $\mathrm{F}$ ratios for scales and indices are presented in Table 1.

Classification analyses were examined for all significant variables. The Es-K Index with a cutoff score of -3 had the best prediction rate, accurately classifying 83.3\% of the deceptive applicants with a sacrifice rate (false positives) of only $5.5 \%$. Using a comparable rate for detection of deceptive applicants for three other scales, the false positive rate was considerably higher, ranging from about $39 \%$ to $44 \%$. The GD scale from the IPI performed slightly better than the basic MMPI validity scales of $\mathrm{L}$ and $\mathrm{K}$; however, the GD mean was considerably lower and its standard deviation somewhat greater. These cutoff scores were "optimal" derivations for this particular group, so the issue of "overfit" is likely to be a significant factor in these rates of classification accuracy. Results of the classification analyses are presented in Table 2 .

\section{DISCUSSION}

The purpose of this study was to examine the relationship between psychometric indicators of defensiveness and conscious deception in law enforcement applicants. The results suggest that, at least to some extent, such a relationship

Table 1. Comparison of Police Applicant Groups on MMPI

Scales and Indices

\begin{tabular}{lccc}
\hline & \multicolumn{3}{c}{ Applicant group } \\
\cline { 2 - 4 } & $\begin{array}{c}\text { Deceptive } \\
n=18\end{array}$ & $\begin{array}{c}\text { Comparison } \\
n=18\end{array}$ \\
MMPI Scale & mean $(S D)$ & mean $(S D)$ & $F$ \\
\hline L Scale & $58.06(8.67)$ & $50.22(5.40)$ & $10.60^{* *}$ \\
K Scale & $66.94(5.65)$ & $62.11(7.33)$ & $4.91^{*}$ \\
Total O-S & $-88.33(33.18)$ & $-71.89(34.30)$ & 2.14 \\
Mp Scale & $18.39(3.78)$ & $15.72(3.79)$ & $4.48^{*}$ \\
F-K Index & $-18.39(3.48)$ & $-15.89(5.61)$ & 2.58 \\
Es-K Index & $-7.00(4.31)$ & $2.22(5.59)$ & $30.72^{* * *}$ \\
GD Scale & $49.39(8.71)$ & $43.06(8.59)$ & $4.82^{*}$ \\
\hline${ }^{*} p<.05 .{ }^{* *} p<.01 .{ }^{* * *} p<.001$, two-tailed.
\end{tabular}


Table 2. Classification Analysis for

Significant Variables

\begin{tabular}{lcc}
\hline \multicolumn{1}{c}{ Variable } & True positives & False positives \\
\hline Es-K Index $<-3$ & $15(83.3 \%)$ & $1(5.5 \%)$ \\
GD Scale $>43$ & $15(83.3 \%)$ & $7(38.9 \%)$ \\
K Scale $>63$ & $15(83.3 \%)$ & $8(44.4 \%)$ \\
L Scale $>52$ & $14(77.8 \%)$ & $7(38.9 \%)$ \\
Mp Scale $>19$ & $7(38.9 \%)$ & $3(16.7 \%)$ \\
\hline
\end{tabular}

does exist. These findings also support the utility of several psychometric validity scales of the MMPI and IPI for the assessment of defensiveness/deception in these forensic preemployment screenings.

The traditional validity scales on both the MMPI (L \& K) and IPI (GD) that are designed to detect minimization were significantly different between the groups. Thus, applicants who provide false information on applications or background inquiry may also be more defensive or guarded on psychological testing. Since the distinction occurred for L and K on the MMPI and GD on the IPI, the indication is that the efforts at deception are both naive (more obvious) and sophisticated (more subtle). However, the higher level of significance for the $\mathrm{L}$ scale would suggest that the less sophisticated efforts are used more prominently by deceptive applicants. It is also possible, however, that this evidence of more naive strategies may reflect identification of less sophisticated deceivers. In other words, the criterion group might have only consisted of individuals who were poor liars.

On balance, however, there was no significant difference between deceptive and control applicants with regard to the total number of obvious versus subtle items endorsed on the MMPI. However, these items do more directly assess symptom report rather than a style of defensiveness or minimization. In addition, even "normal" subjects' mean scores are typically in the negative range (Greene, 1988).

With the special scales and indexes from the MMPI, the results were somewhat mixed. The Positive Malingering (Mp) Scale showed a significant difference; however, when subjected to classification analysis with a suggested cutting score of 20 (Cofer et al., 1949), the scale would correctly identify only $39 \%$ of the deceptive applicants and $83 \%$ of the controls. The strongest finding from this study was the efficiency of the Es-K Index, which accurately classified about $83 \%$ of the deceptive applicants with a sacrifice (false positive) rate of only $5.5 \%$. This index shows promise for screening deception/defensiveness in a police applicant population.

Interestingly, the F-K Index and Obvious vs. Subtle total did not show a significant difference between the two groups. Though the efficiency of the F-K index for detecting defensiveness/minimization has not been well documented in clinical contexts (Cofer et al., 1947; Grayson \& Olinger, 1957; Johnson, Klinger, \& Williams, 1977), other research has found it to be more effective in criminal forensic and police officer populations (Grossman et al., 1990; Wasyliw et al., 
1988). A similar trend has been found for the O-S difference (Grossman et al., 1990). One possible explanation for the discrepancy between our results and previous findings may be a difference in the criteria. Whereas previous studies examined motivational sets involving level of psychological/symptomatic disturbance, the criterion of deception in the present study did not necessarily relate to report of symptoms but rather a "style" of trying to conceal or minimize problems to appear more favorable as an applicant.

It should also be noted that for the total Obvious-minus-Subtle score and the F-K Index, the means for both groups were within or close to the range that would indicate minimization ( -11 for F-K, Gough, $1950 ; \&-75$ for O-S, Wiener, 1948). This suggests that, if these indexes are to be used in law enforcement assessments, different cutting scores may need to be applied. This finding is consistent with previous research that recommends using more liberal cutoff scores for use of these validity indicators with a law enforcement population (Grossman et al., 1990).

There are, however, some potential limitations to this study that should be addressed. First, although an admission of lying is an unbeatable criterion for deception, it also poses a potential problem. Namely, the possibility that only unsophisticated deceivers are being identified and that therefore the population may be somewhat skewed and not representative of individuals who are effective at deception. This reflects the criterion problem in doing any type of research in deception or malingering. It is also difficult to distinguish whether such individuals produce these scores because they are prone to lying or because they are overly defensive as a result of problems in their background.

In considering these issues with regard to the present study, we note that although the participants were classified as deceptive based on an admission, that admission typically came only after they were confronted with objective evidence of their deception. None of those who were confronted denied their dishonesty. As for the question of whether to attribute the scores to being "lie prone" or to being overly defensive based on a problematic history, this distinction may not be critical for law enforcement applicant screening. In both cases, there is a propensity to distort information for personal gain and refuse to acknowledge fault. Although the job selection process carries an inherent bias toward presenting favorably, the deceptive participants in this study intentionally lied and/or falsified sworn and notarized documents in order to cover up some potential difficulty. This goes beyond the acceptable scope of positive impression management and calls into question the integrity of the applicant. It is this characteristic that could be problematic in a sworn law enforcement officer.

A more important limitation is the small number of participants and the resulting "overfit" in established cutting scores. Such a limited sample size necessarily limits the generalizability of these findings. Because these cutoff scores were optimally derived for this specific group, there is likely to be lower classification accuracy when they are applied to other groups. There is clearly a need for cross-validation of these findings. It would also be interesting to replicate this study using the MMPI-2 as all of the indicators except the Mp scale have been retained at least in a modified form. Based on reports of equivalency between the 
instruments (Butcher, Dahlstrom, Graham, Tellegen, \& Kaemmer, 1989), these findings from the MMPI should also apply to the MMPI-2.

In summary, these scales and indexes show some promise for identifying deception in law enforcement applicants. Although they will not categorically identify or distinguish dishonest candidates, they may provide valuable information that the psychologist could use to raise the index of suspicion for a given individual. The psychologist should review several test indicators and use these in combination with the interview and collateral documentation.

Preemployment psychological screening of law enforcement candidates places a heavy ethical and legal burden on psychologists. In conducting these evaluations, it is important for the mental health professional to acquire accurate background and historical information. In addition to the content of this information, the applicant's honesty in disclosure is also of crucial importance. Psychologists should enter these preemployment evaluations with a relatively high index of suspicion for deception. By combining multiple psychological tests with multiple sources of collateral information, and a structured clinical interview, the probability of identifying a deceptive or dishonest applicant increases (Ostrov, 1986). Though additional research is clearly needed, we hope that these findings will be seen as a first step in developing methods for the detection of deception in law enforcement applicants.

\section{REFERENCES}

Barron, F. (1953). An ego strength scale which predicts response to psychotherapy. Journal of Consulting Psychology, 17, 327-333.

Barron, F. (1956). Ego-strength and the management of aggression. In G. S. Welsh \& W. G. Dahlstrom (Eds.), Basic reading on the MMPI in psychology and medicine (pp. 579-585). Minneapolis, MN: University of Minnesota Press.

Bonsignoire v. City of New York, 521 F. Supp. 394 (1981).

Butcher, J. N., Dahlstrom, W. G., Graham, J. R., Tellegen, A., \& Kaemmer, B. (1989). Minnesota Multiphasic Personality Inventory -2: Manual for administration and scoring. Minneapolis: University of Minnesota Press.

Caldwell, A. B. (1988). MMPI supplemental scale manual. Los Angeles: Caldwell Reports.

Cofer, C. N., Chance, J., \& Judson, A. J. A. (1949). Study of malingering on the MMPI. Journal of Psychology, 27, 491-499.

Colligan, R. C., Osborne, D., Swenson, W. M., \& Offord, K. P. (1983). The MMPI: A contemporary normative study. New York: Praeger.

Conte v. Horcher, 50 Ill. Appl. 3d 151 (1977).

Gredreau, P., Irvine, M., \& Knight, S. (1973). Evaluating response styles on the MMPI with prisoners: Faking good adjustment and maladjustment. Canadian Journal of Behavioral Science, 5, 183-194.

Gough, H. G. (1950). The F minus K dissimulation index for the MMPI. Journal of Consulting Psychology, 14, 408-413.

Graham, J. R. (1987). The MMPI: A practical guide. New York: Oxford University Press.

Grayson, H. M., \& Olinger, L. B. (1957). Simulation of "normalcy" by psychiatric patients on the MMPI. Journal of Consulting Psychology, 21, 73-77.

Greene, R. L. (1980). The MMPI: An interpretive manual. New York: Grune \& Stratton.

Greene, R. L. (1986) [MMPI data research tape for normal adults and college students.] Unpublished raw data. 
Greene, R. L. (1988). Assessment of malingering and defensiveness by objective personality inventories. In R. Rogers (Eds.), Clinical assessment of malingering and deception (pp. 123-158). New York: The Guilford Press.

Grossman, L. S., Haywood, T. W., Ostrov, E., Wasyliw, O., \& Cavanaugh, J. L. (1990). Sensitivity of MMPI validity scales to motivational factors in psychological evaluations of police officers. Journal of Personality Assessment, 55, 549-561.

Grow, R., McVaugh, W., \& Eno, T. (1980). Faking and the MMPI. Journal of Clinical Psychology, 36, 910-917.

Harvey, M. A., \& Sipprelle, C. N. (1976). Demand characteristic effects on the Subtle and Obvious subscales of the MMPI. Journal of Personality Assessment, 40, 539-544.

Hathaway, S. R., \& McKinley, J. C. (1967). MMPI manual (rev. ed.). New York: Psychological Corporation.

Heilbrun, K. (1992). The role of psychological testing in forensic assessment. Law and Human Behavior, 6, 257-272.

Hunt, H. F. (1948). The effect of deliberate deception on MMPI performance. Journal of Consulting Psychology, 12, 396-402.

Inwald, R. E. (1985). Proposed guidelines for conducting pre-employment psychological screening programs. Crime Control Digest, 19 (11), 106.

Inwald, R., Knatz, H., \& Shusman, E. (1982). Inwald Personality Inventory manual. New York: Hilson Research.

Kelly, D. B., \& Greene, R. L. (1989). Detection of faking good on the MMPI in a psychiatric inpatient population. Psychological Reports, 65, 747-750.

Johnson, J. H., Klinger, D. E., \& Williams, T. A. (1977). The external criterion study of the MMPI validity indices. Journal of Clinical Psychology, 33, 154-156.

McCabe v. Hoberman, 33 A.D. 2d 547 (1st Dept. 1969).

Meehl, P. E., \& Hathaway, S. R. (1946). The K factor as a suppressor variable in the MMPI. Journal of Applied Psychology, 30, 526-564.

National Advisory Commission on Criminal Justice Standards and Goals: Police (1967). Washington, D.C.: U.S. Government Printing Office.

Ostrov, E. (1986). Use of multiple sources of information when doing mandatory psychological evaluations of police officers. In J. Reese \& H. Goldstein (Eds.), Psychological services for law enforcement (pp. 291-298). Washington, D.C.: Federal Bureau of Investigation.

Pendergrass, V. E. (1987). Psychological assessment of police for entry level selection. The Chief of Police, 2(1).

Peterson, G. W., Clark, D. A., \& Bennett, B. (1989). The utility of MMPI Subtle, Obvious scales for detecting fake good and fake bad response sets. Journal of Clinical Psychology, 45, 575-583.

Wales, B., \& Seeman, W. (1968). A new method for detecting the fake-good response set on the MMPI. Journal of Clinical Psychology, 24, 211-216.

Weed, N. C., Ben-Porath, Y., \& Butcher, J. N. (1990). Failure of Wiener and Harmon Minnesota Multiphasic Personality Inventory (MMPI) Subtle scales as personality descriptors and as validity indicators. Psychological Assessment: A Journal of Consulting and Clinical Psychology, 2, 281285.

Wasyliw, O. E., Grossman, L. S., Haywood, T. W., \& Cavanaugh, J. (1988). The detection of malingering in criminal forensic groups: MMPI validity scales. Journal of Personality Assessment, $52,321-333$.

Wiener, D. W. (1948). Subtle and obvious keys for the Minnesota Multiphasic Personality Inventory. Journal of Consulting Psychology, 12, 164-170. 